\title{
Pedagogical Study on the Meaning of Mathematical Structure
}

When constructing and carrying out mathematics curricula, we first encounter an important question: "What shall we teach?" As an answer to this question, Bruner suggests in his book, The Process of Education(1960), that the structure of mathematics should be taught. This idea gains much support in the education world because it is accepted as an alternative to the existing education system where only piles of facts or "middle language" is being taught.

What does teaching mathematical structures to students mean? If a math teacher teaches high school students commutative law, associative law and the existence of inverse element and identity element as the properties of the real number system, is he teaching the algebraic structure? For students, who do not know the concepts like group, ring and field and also have not noticed the similar phenomena in a set of polynomials, a set of functions and a set of matrices, the algebraic structure presented as above is likely to be a skeletonlike structure extremely poor in context. In other words, if students, who have already gotten familiar with the 


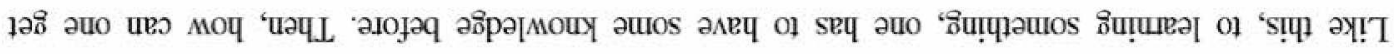

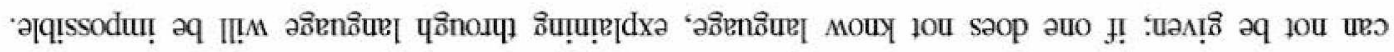

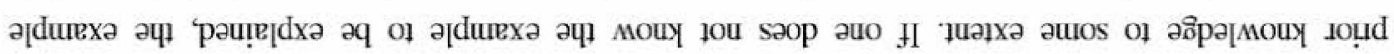

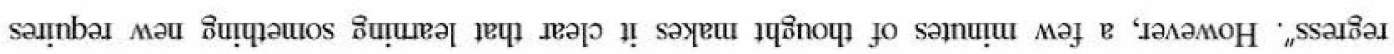

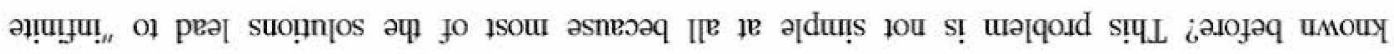

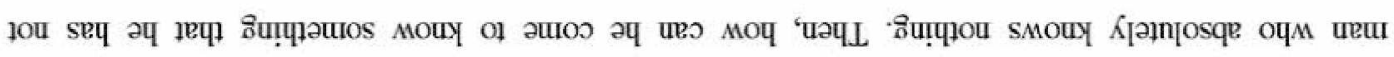

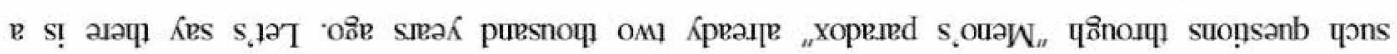

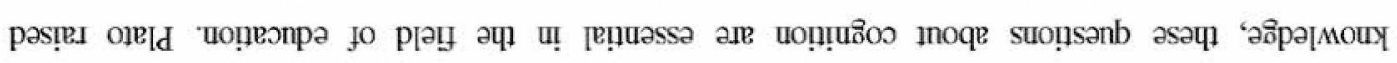

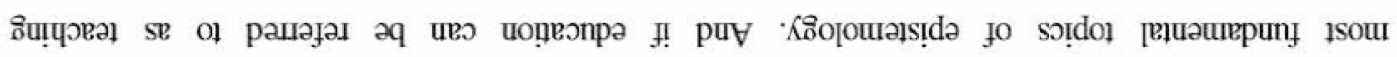

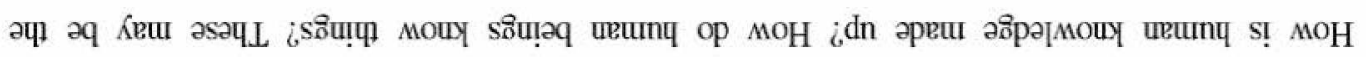

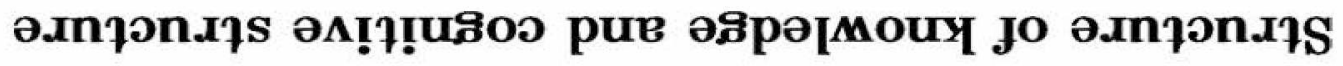

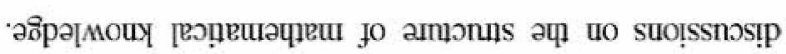

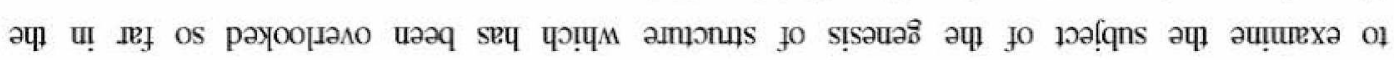

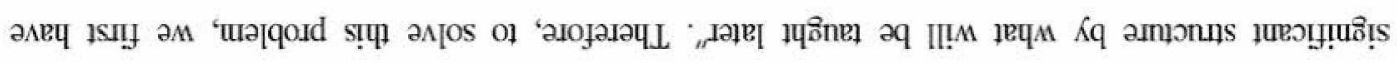

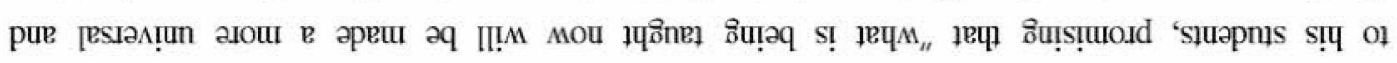

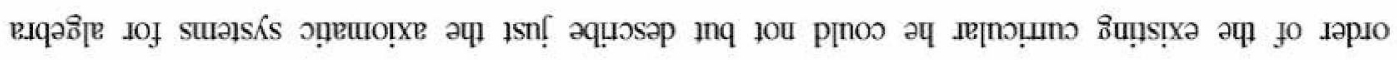

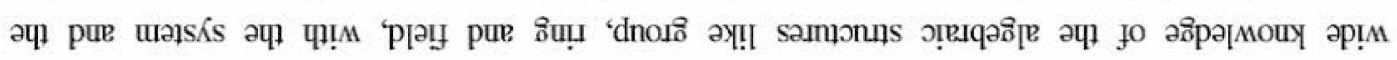

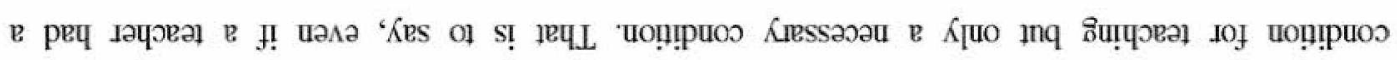

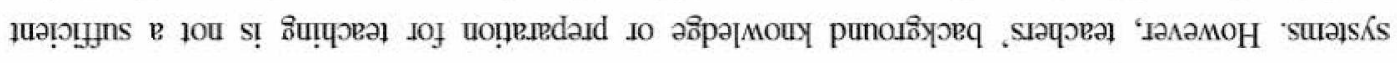

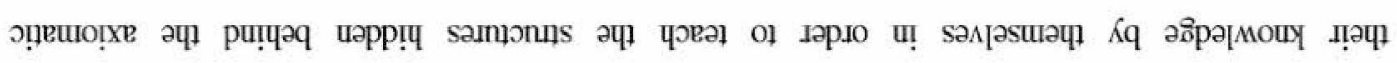

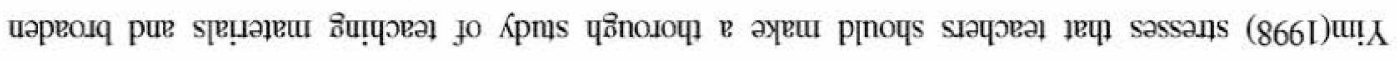

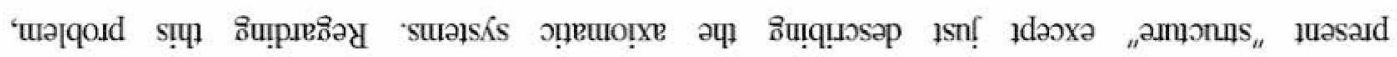

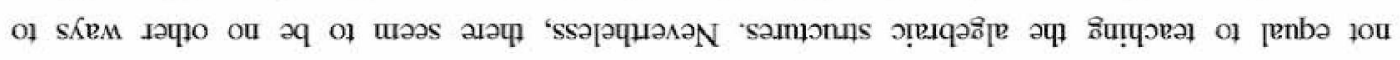

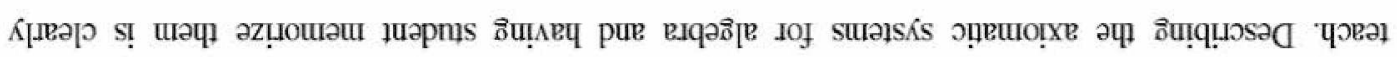

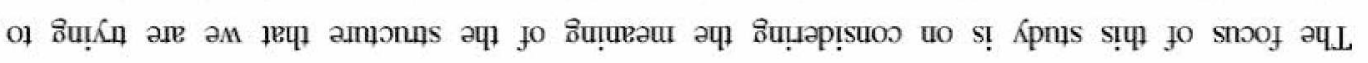

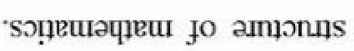

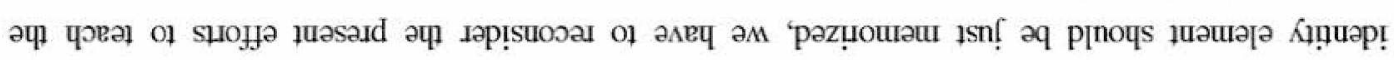

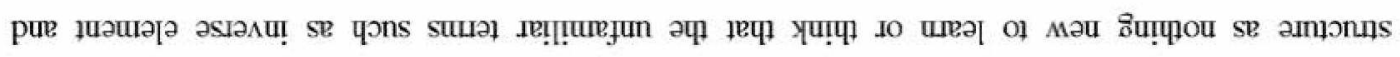

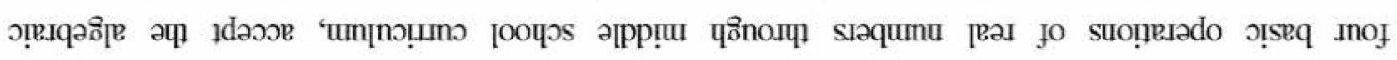


the "prior knowledge"?

Plato's answer to this question is "anamnesis" - that is, not knowing means forgetting what one used to know in a previous life and therefore, leaming is just recollecting it. In conclusion, Plato's answer suggests that if one does not know something, he is never able to learn it. In other words, structure(or essence) of knowledge or form of cognition independently exists from the beginning. This can be seen as an objectivistic and realistic point of view that epistemology before Kant has. The reason why this attitude is thought objectivistic is that it regards human cognition as a copy of "an object which is formed and defined by itself" and, thus, emphasizes the predominance of the object over the subject of cognition. According to the objectivism, knowledge is just to find or represent the objective and ultimate entity and the knowledge of subject of cognition is defined by this objective entity.

However, the development of modern natural science made it clearer that natural science is not the discovery of objective nature but a way of interpreting natural phenomena. According to Kuhn(1970) who explains the progress in science with the term of "paradigm", normal science is governed and given authority by a paradigm but when a new competitive paradigm is brought in, problems arise-that is to say, the existing paradigm and the new one see the world in each different way and describe it in each different language; within a new paradigm, a concept can have totally different meanings from the ones within the old paradigm, because the new paradigm changes its relation with other concepts. In this regard, progress in knowledge is made not by accumulation of fixed entities but by qualitative changes and requires dialectical reconstruction which integrates the old paradigm and the new one in a comprehensive frame. And the whole frame of the constructed knowledge can be called "structure". What is important here is that the structure is based on human activity which can be considered before distinguishing between a posteriori "matter" and a priori "form" that modern epistemology tries to take as an objective foundation. Therefore, the authority(or validity) of knowledge is autonomously controlled by the activities of those who pursue the knowledge.

This argument that human cognition can not be explained on an objective foundation is in some accordance with Piaget's genetic epistemology. Piaget expounds his operational constructivism can be reduced neither to empiricism nor to apriorism as follows.

In conclusion, the operational constructivism suggested by genetic analysis is reduced neither to empiricism nor to apriorism, because we could not derive intelligence itself from objects and because the subject does not possess frameworks which contain all reason in advance, but only a certain activity which allows him to construct operational 


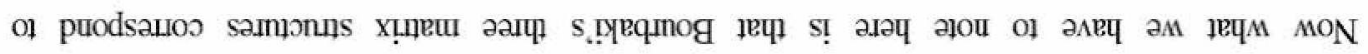

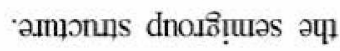

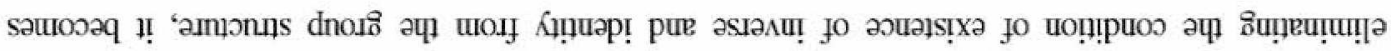

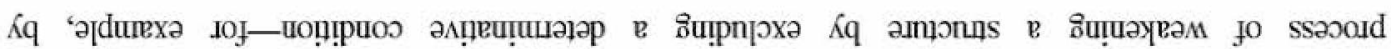

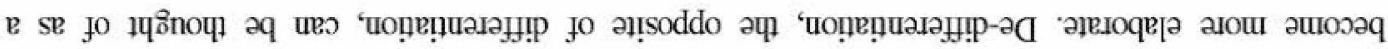

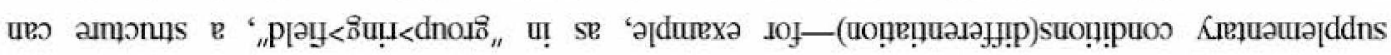

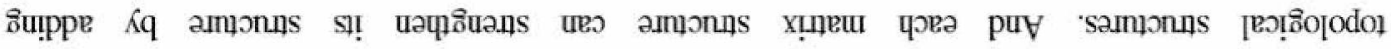

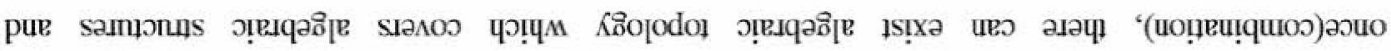

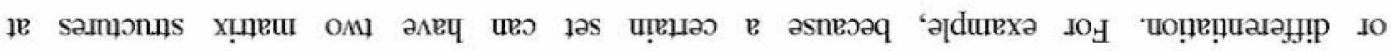

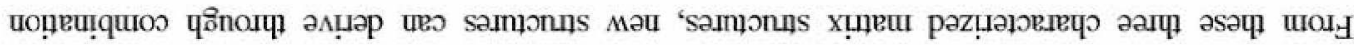

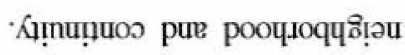

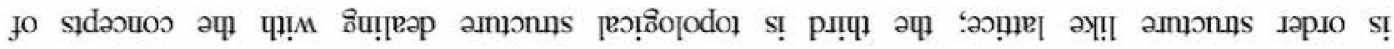

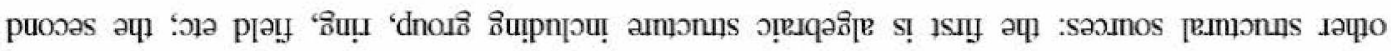

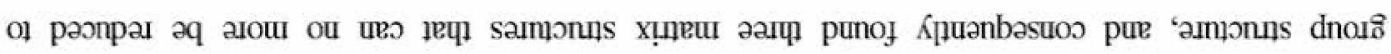

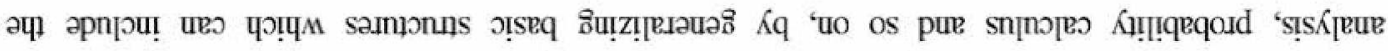

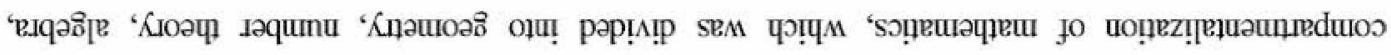

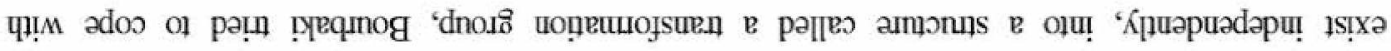

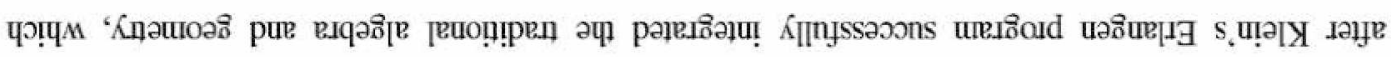

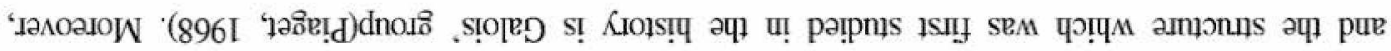

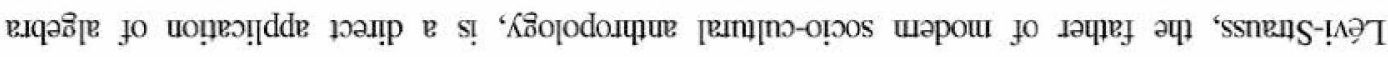

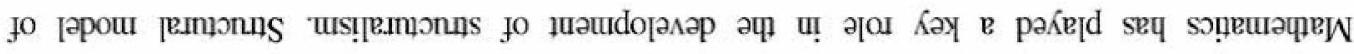

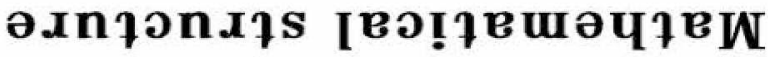

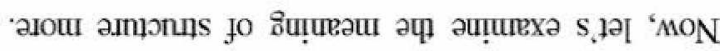

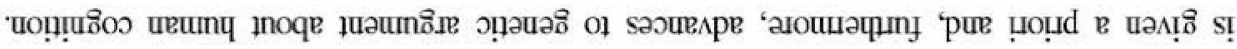

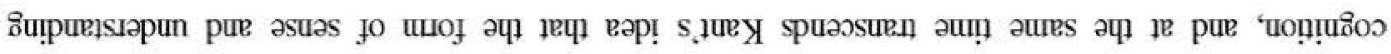

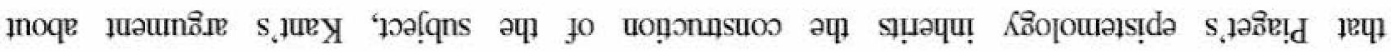

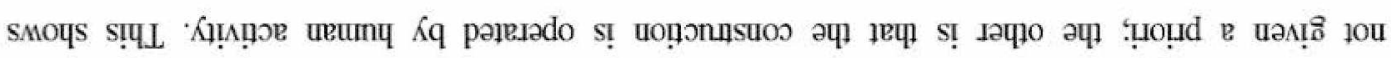

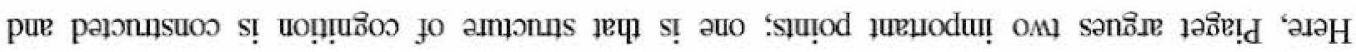

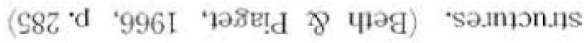


chiliten's structure of logkco-mathematical thought analysed by Piaget(Beth \& Pinget, 1966). Piaget understands the nature of though as operation and refers to an integrated structure nade up of operations as grouping. According to him, hite structures of concrete operations are explatind by 9 groupings in tems of class or relation(Lee, 1973), Operations the classification or seriation constiute the groupings 1 )

Reversibility is an essental characteristic which draws the fine between operations and ordinary actions and therefor, operations can be categorized according to which forn of reversilitity they have, In short, teversibility can be seen as the permanent possibility that a operation will be able to return to its starting point(Lee, 1975), The foflowing example illustrates other forms of reversibility. Given a balance at equilibrum, when an object is placed on one of its sides, it lose the equilibrim. Equilihium is restored either by removing the object or by placing ant equivalent weight on the ofher side of the balance; the former is called inversion or negation; the latter is called recipucily of compensation. Generally, in operational systems related to a set, like classiffcation, reversibilty is in the form of inversion; in operational systems related to asymmery, ike seriation, it is in the forn of reciprocity.

In terms of the inchasion retation of the set $A+A^{*}=B$ is adding $A^{*}$ to $A$ and $B+\left(-A^{2}\right)=$

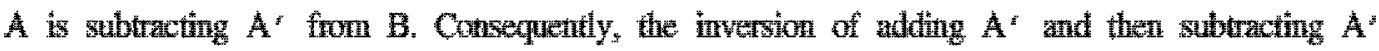
can be represented as $\left(+A^{\prime}\right)+\left(-A^{\prime}\right)=0$. As for Bourbaki's three matrix struchures, we can find that the algebrate structures have the same fom of reversibility. If $\mathrm{T}$ is an operation and $\mathrm{T}^{-1}$ is its triverse oferaton, the relation of $\mathrm{TT}^{-1}$ me e ts connon to all algebraic structures.

On the other land, onder sinuctures are characterized by the fact that revervibility in these structres appears in the form of reciprocity: by adtiting $B \leq A$ to $A \leq B$, geting $A=B$. This is the same structure as of the example of a balance; that is, when an object is placed on one of

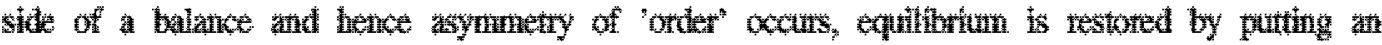
equivalent weight on the ofher side.

Paget classifies pperations into thres categories according to whether the reversibility of the operations is in the form of invertion, reciprocity or continuity and separation, and argues that these categories exactly corespond to Boubakfs three matrix stmctures. Acording to Piaget(Plaget, 1968), algebraic stnctures correspond to classification and number, order structures to sequential arrangenent, sequettial correspondence and seration; fopological struetures to operations naking classes which are distinguished not by similarities or differences but by the

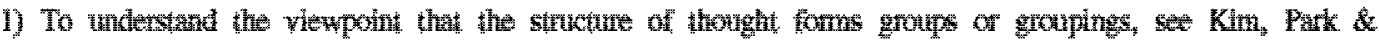
Woof 1984$)$, pp. 134143 . 


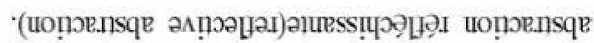

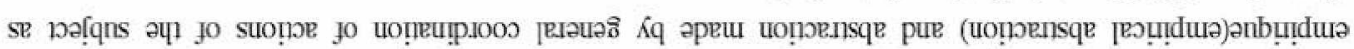

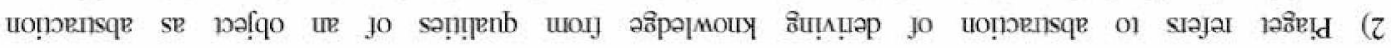

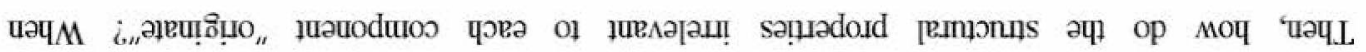

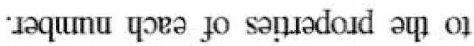

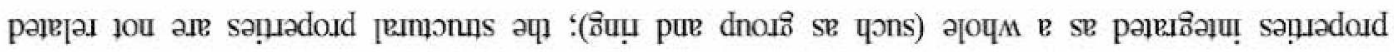

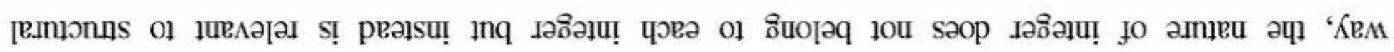

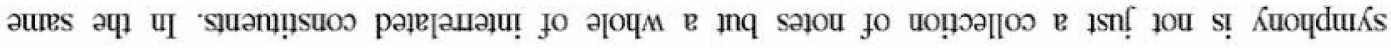

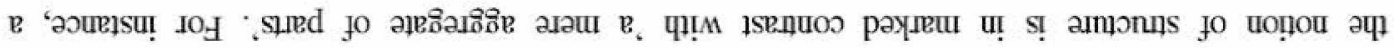

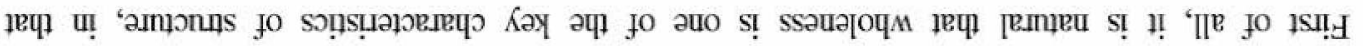

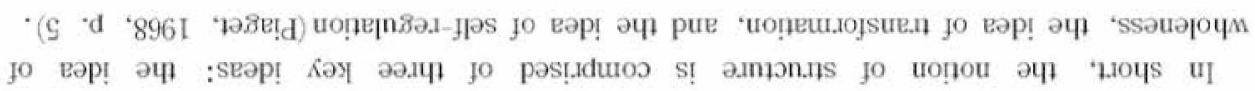

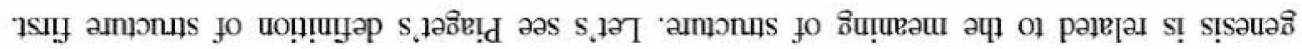

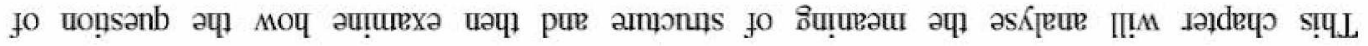

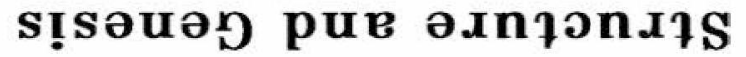

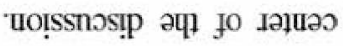

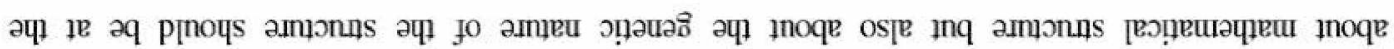

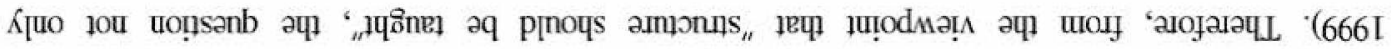

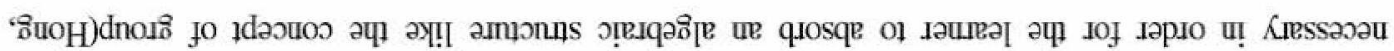

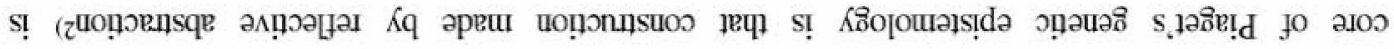

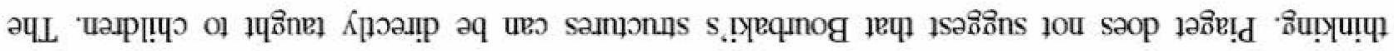

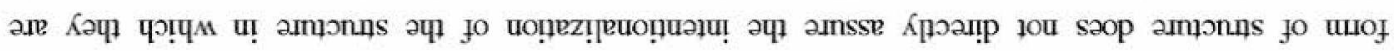

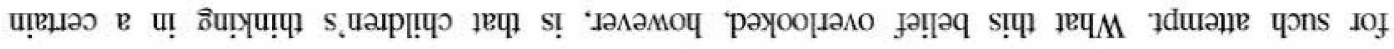
А!!р!

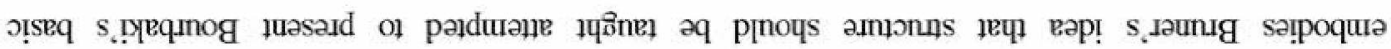

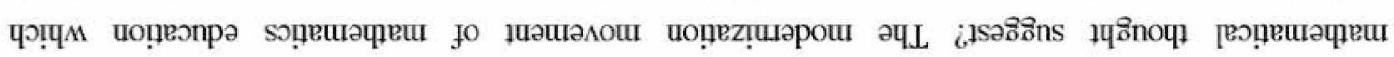

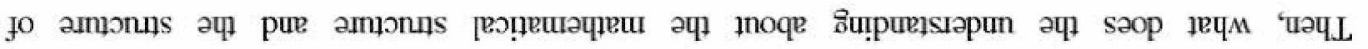

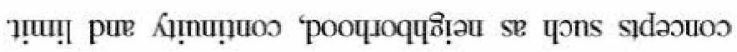


tinerptefed in the light of eptstemology, this problem beomes similar to Meno's paradox. When a child constructs cognition, does he or she have an infate tool for assimilating each constituent or do the constinents get together and then the stmctural properties just originate? Athough structuration focuses on the wholeness as mentioned above, the structuralism can be sad to regress to metempirical platonism if tis viewpoint on the genesis of structure is retated to the former questios; the structuralism can be said to regress to the combination of empiticisn and atomisn if it is related to the latter one. Piaget thinks that neither of viewpolnts give the satisfactory soution to the problem and presents a new standpoint-operational structurafiem. It suggests that structural properties neither exist a priori nor stem directy from constituents but cone fron relation among consitiments, or "opertiton".

From this point of view, transfornation becomes a key charateristic of simcture ln fact, every struchure can be seen as a system of transtomation. In the algebraic structure of natural number, three pits two making five or forr following thre is an example of transformation and operation is the wile of the transfomation. As struchuralism becones mone elaborate, it aproaches the idea of transformation more closely: the idea of transfomation is not found in the theory of Stussure. the futher of structuralism bat later it beomes a key idea of Chonsky's "transformational-generative grammat". In the case of Bruer, he interptets structure as a fixed entity from the vewpoint of realism and fails to understand structure as systems of transformation for he argues that scholats" knowledge and children's knowledge share the same structure and the differences between the two conte fron only the way of expression(Hong, 1999).

One of the central ideas of Pinget"s ineory is that the sysiem of transfommation and operation develops. Beaase chithen below six usually do not have reversibility in activities such as chasification or seriation, they can be sad to be at the semi-logical stage of intellectual

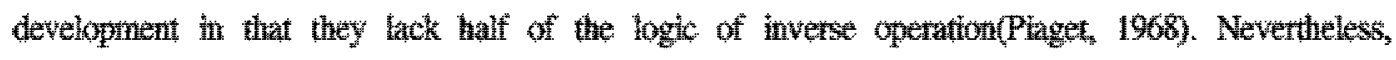
the concepts of function and identify -even though they are ndimentary- exist at this stage. In concrete operational period when chithen accuire reversibility, the concept of number is constructed by transitivity of relation, quantification of classification, seriation and inclusion relation and thereby the system of operation gatns the senigroup stuchure: In formal operational period when inversion and reciprocity, two forms of reversibility, are coordinated, the system of operation gains INRC group? or Klein 4-group.

Now, the only problem is for what reason this structure of operation is able to develop. Piaget

3) When I stands tor ldentity, $\mathrm{N}$ for negation; $\mathrm{R}$ for reiprocty; $\mathrm{C}$ for correlation betwen negation and redprocity, these saisty $\mathbf{I}^{2}=\mathrm{N}^{2}=\mathrm{R}^{2}=\mathrm{C}^{2}=\mathrm{I}, \mathrm{NRC}=\mathrm{I}, \mathrm{NR}=\mathrm{C}, \mathrm{RC}=\mathrm{N}, \mathrm{CN}=\mathrm{R}$. 


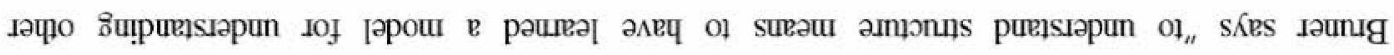

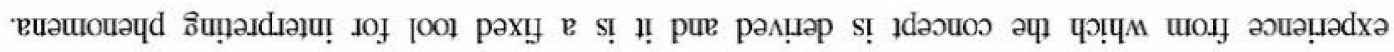

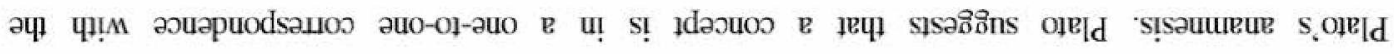

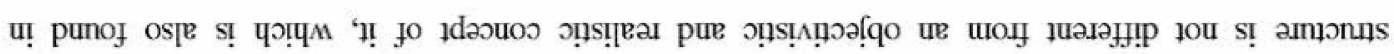

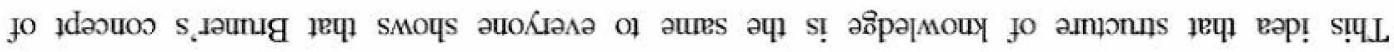

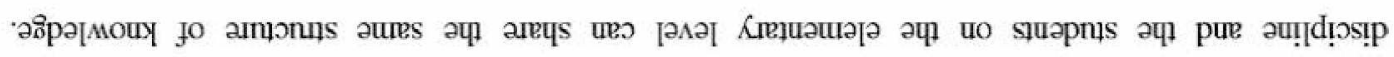

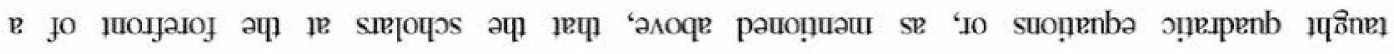

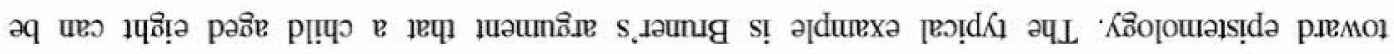

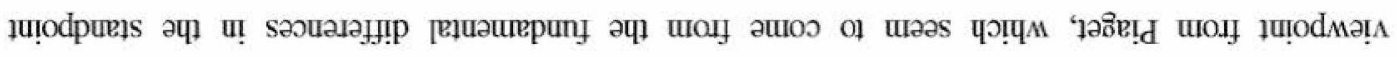

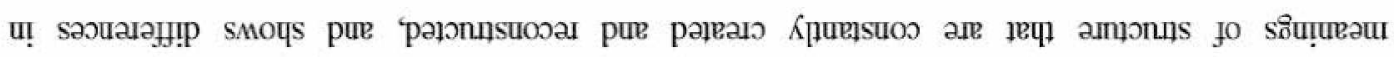

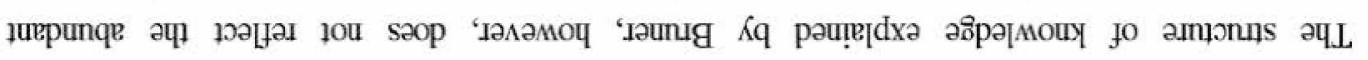

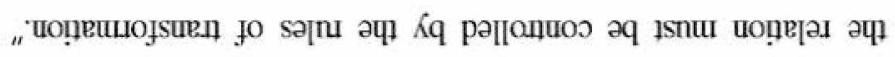

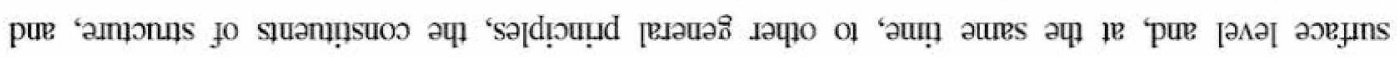

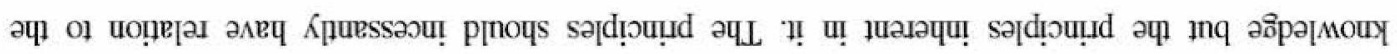

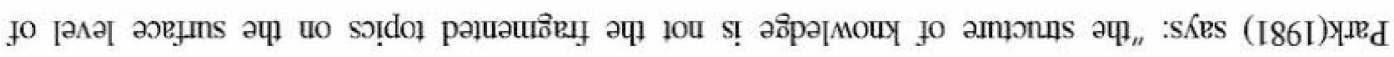

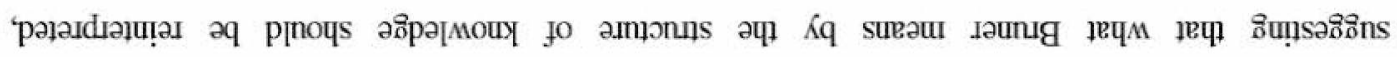

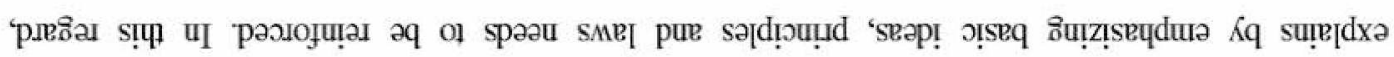

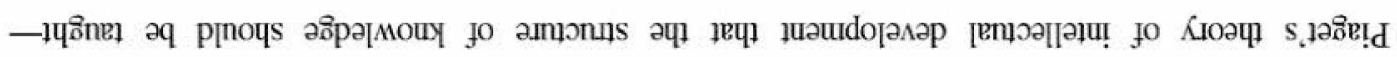

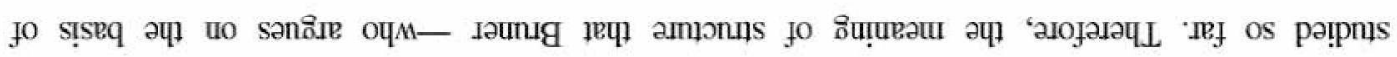

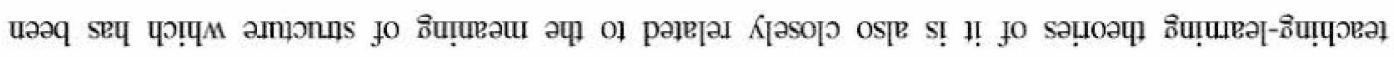

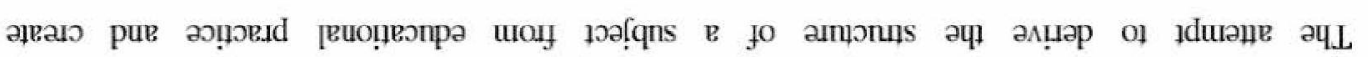

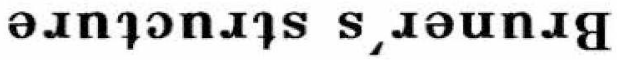

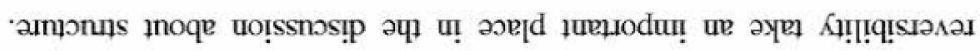

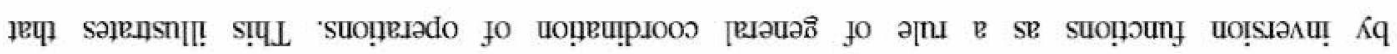

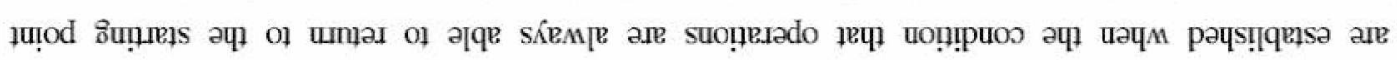

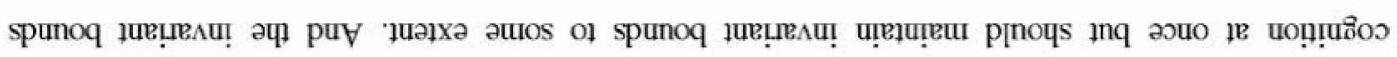

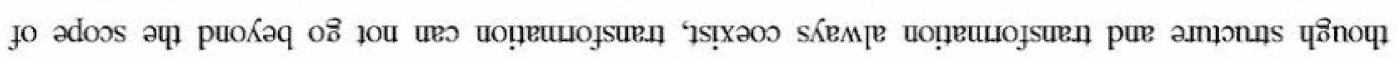

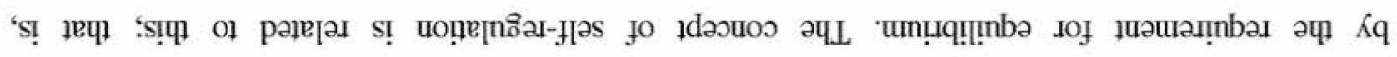

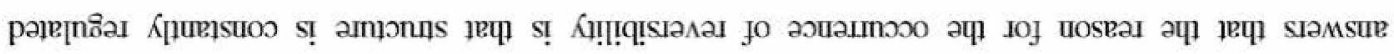


things like it that one may encounter" and "these basic ideas should be isolated and taught more explicitly in a manner that frees them from specific areas(Bruner, 1960)." But the problem of this explanation is that the knowledge here is explained in the light of atomism. Especially in the case of mathematics and science, knowledge is a system of concepts rather than a gathering of individual facts and information. In the same context, Piaget stresses the wholeness as one of the characteristics of structure. A separate fact does not bear a fixed meaning and its meaning varies according to its context. Bruner himself says it is undesirable to teach just piles of facts, but a separate basic idea may also be reduced to just a fact if it loses its whole context.

Besides, though Bruner's intention can be understood as emphasizing structure as a system or interrelation among concepts, the problem that scholars' knowledge and children's knowledge should have the same structure is still unsolved. The differences between professional scholars' knowledge and children's knowledge come neither from differences in quantity nor from differences in the methods of representation. As Piaget says in his explanation of the generalization by reflective abstraction(Piaget et al., 1977), the differences in the structures of different levels contain qualitative gaps. In addition, as Piaget explains with the phrase of "self-regulating transformation", cognitive structure and, further, the structure of knowledge are not being fixed but being incessantly modified toward the ideal form. But Bruner regards structure as a fixed tool for interpreting phenomena. Like this, he fails to define the concept of structure thoroughly and as a result - unlike his intention- his theory regresses to an objectivistic and realistic standpoint.

\section{Representation vs. Operation}

According to Piaget, knowledge has an operative aspect and a figurative aspect. The two aspects are also called "schème" and "schéma" respectively; schème means a general structure that makes actions and operations possible and generalizes them; schéma means representation or image of the result from a certain action or operation. Perception, imitation, image and so on, which Piaget calls a figurative aspect can not be the essence of knowledge and they can have meanings only through actions or operations. Especially logico-mathematical knowledge sometimes does not have the figurative aspect 4 ).

4) A typical example is cardinality of natural numbers. This can be understood only after recognizing 
As for the essence of logico-mathenatical concepts, Paget explained as follows: "first, the structure of a blological organism (the starting point) leads to a sensoti-motor scheme and, then according to it, atiots are coodinated, resulting in reflective abstraction, by which operations are constructed, and based on them, higher-level operations are formed; it is the operations and the bigherlevel operations that are the essence of logico-nathematicat concepts"(Kim et al., 1984). Fron Piaget's viewpoint, logico-mathenatical concepts slould not be derived from enpinical contents but it shoutd be constnucted by operational fornss and therefore, reflective abstraction is obviously different from empirical abstruction. In addition, although the subject of cognition has to go through representationfepresentation) of his actions in order to coordinate them, representation is needed only the first stuge, where reflechissement starts, of the whole process of reflective abatracton, which is made w of a cycte of reflechissement and reffexion(iaget et al., 1977). The fact that this representation is possible ts just an evidence showing that the subject of cognition intemalized his actions. Moreover, the reflechissement is fintshed only after the subject of cogninion makes reflexton start trough thenatisation of his intemalized actions and, this, it is naturally imposible that the mathematcal concepts requiring reftective abstraction are completely explained by only representation.

Bruner's idea of three representation need to be reconsidered in this regard. His suggestion that the structure of a stbject should be translated and then presented to children inplies that the teather shoud assimilate new knowledge to the student's existing cognitive structure by transiating the knowfedge into the nock of representation, which is easy for the student to understand and then presenting it However, this is unacceptabte, consiffering Piaget's genetic epistemology which enphasizes the childen's cognitlye structure evolves through qualitative changes. As studied above, Piagets genetic epistemology or Popper"s and Kuhn's theory of scientific history shows

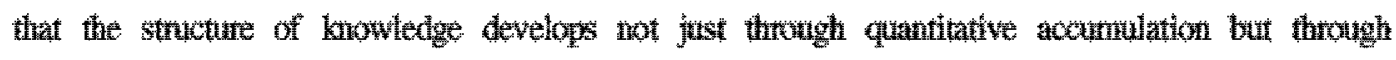
incessant modffications and transfomations. If the nature of knowledge is 30 , teaching is not transfating new knowledge into already known simuations for students but making them look upon the alfeaty kwown stuations as new fools for interpretation and, in the long run, instructing them to see even the fanilhar stuations in more thoughtprovoking way. As in Bruner's WS theory, the educational situation where the leaner just accepts the mode of representation presented by the teacher does not reflect that the learner's cognitive sintoture changes and therefore it cannot be

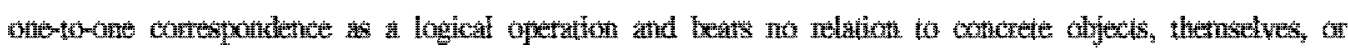

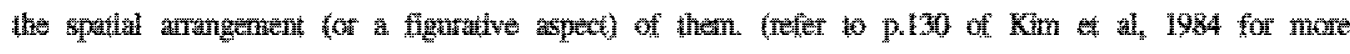
examples). 
said that new learning has actually happened. Between knowing if one move out farther from the center of a see-saw, he or she goes down father and understanding Newton's Law of Moments, there are qualitative differences in cognitive structure and the differences are logical gaps more than just the differences in representation. Nevertheless, if the teacher tries to teach the fundamental principle of Law of Moments using enactive representation such as a see-saw and a balance, the student is likely only to accept the principle superficially on his level at that time.

Moreover, Bruner thinks that if the instructor presents the representation which is higher than the student's stage of development, the challenges which are derived from the gap between the two cause new learning. But from Piaget's point of view, representation is just a product of cognition at its level and at the next level of cognition it works only as a concrete object but it cannot be a source of new cognition. The ideas) that presenting various kinds of representation makes new cognition happen comes not from the viewpoint that the subject constructs cognition but from the realistic viewpoint that the subject just copies objective objects of cognition.

In the case of logico-mathematical concepts, particularly, their essence is not representation but operation, as Piaget points out. In addition, mathematical structures, concepts, methods of proof, algorithms, propositions, theorems and so on are all schèmes and mathematical activities include all activities of constructing and applying these operational schèmes. The learner can construct new mathematical concepts only through reflective abstraction based on his operations as the objects of cognition and after that he is able to understand representation, presented by the teacher. in his own way.

\section{The learning of algebraic structures}

So far we have studied essential characteristics of structure such as wholeness, transformation and self-regulation. Now it is time to consider the situation where the instructor tries to teach algebraic structures to the student. The problem here is how the formalized algebraic structures assimilate to the learner's cognitive structure. For instance, if the reason for teaching the group structure is that it is the most fundamental and essential part of mathematical thought, it is wondered how closely learning the simple fact that "the a set of real numbers has such and such characteristics" approaches to the learning of structure that is originally intended6). According to

5) A similar argument is found in Dienes" "perceptual variability principle". 
Pinget(1986), reflective alstraction, fhe mechanisin by which structure gets note elaborate and refined, plays a key role not only in the process where logico-nathematical thought acquires the grow structure but also in the process where the leaner grasps the concept of group as the fesult of thematizing and mentionalizing the thought If teaching algebraic structures is neossary, the most important principle of teaching structure shoold be that algebraic structures should be constructed through the abstraction and the generalization of the leanker's way of thinking and mathematical experiences.

The concept of gromp is a basic concept of moden algebra and noreover since its uility is very conprehensive, it is intoduced to annost all fietds of mathematics, logitos, physics and so forth. Piaget(1968) even says grow is the prototye of geteral structures. And he also explains the reason the concept of group is very comprehensive and sacesssfin is that the concept is acquired by reflectlye abstraction, the speclal way of logico-mathematical abstraction. When a certain propery is atsuracted fron the things that have the property, the more generat the propery boomes (dhe more is extension extends), the narrower its intenston becones and as a result the utility of the stmcture decreases. On the other hand, when a concept is abstracted from operations(the ways of operating on things), the nore generatixed the concept is, the richer its intension becones and thas the attity of the structure becomes more comprehensive.

Mearwhile, becatse the concept of grow is derved through reflective abstraction, or through abstraction of varioss operations, general coottination rutes, that is, basic nethock of coordinating operatons, should be first analysed in order to analyse the stucture of the concept. As examined above, since the system of transformation should be self-regulated within certain bounds so as to have a form of structure, at twast two basic ruls of coordinating operations are needed as follows(taget 1968): 0 An operation must be able to return to its stating point all the time (through inverion), 2 The whtmate results of operations nust be independent of the chosen attemative course.

In conparizon with mathematical deftition of the concept of group, the nule $(1)$ is related to the existence of inverse elenent; the rute $\mathcal{P}$ to the associative law. In conchsion, this shows that the group stucture is a representative stucture that contains essential characteristics of the structure of operations or the stmcture of mathematical thought.

Since the agebnatc structires are funclanentally the transfomational system, just presenting the

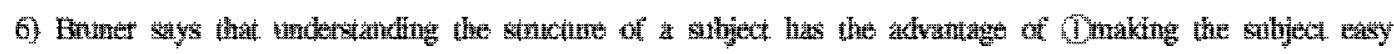

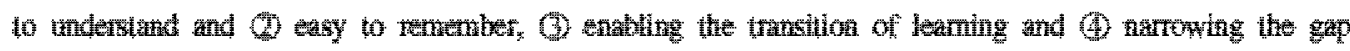
betwen advanced howledge and elementary knowledge. 
ultimate form of formalized structures is not an appropinate way to teach the algebraic structures to the student. Piaget(1968) stresses that "structure" is not correspondent to "form". According to him, the thought of structure as the transformational system is in succession 10 the thought of construction a a continual process of formation, In this regard, Braner's so-called descending curriculun which Just fowers the level of the formalized structure of knowledge in the order from the high school to the midde school and to the elenentary school cantot be said to conform to the viewpoint of structuralisn. Accotding to Freudenthal(1991) who defines structure as a tool for organizing mathematical phenomena or nathematics itself, since in order to belp the learner find and criganize mathenatical structures the content and form of mathematic must be diafectically Interwoven and levelled up, the instnctor should star with the reality of the tearner's level and then seck to systemize it into mathenatically refined structures instead of translating formatizat structural results of mathematics into the language that the leamer can anderstand.

fn other words, instead of presenting complete stnctures of mathematics to the learrer, the

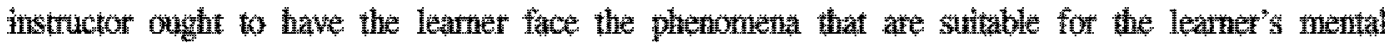
reality and where nathenatical suctures can becone a tool for systemization and let the leamer

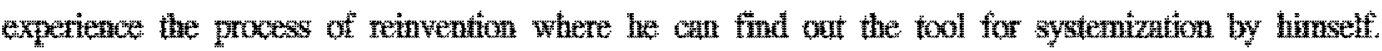
When an instructor let a leaner deal with the tools for organization in the phenonema first, the Fearner constructs the mental objects of mathernatical objects and then is expected to attain then a rise in level of tandertanding through the proces of reflection. Sinilarly, in teaching algebrate struetures inchuding group, the instructor stould present the phenonena, which will be mathematized, to allow the leamer bo consinut the mental objecs of algebraic stmetures and lead him to turn the stuctures into mathematical concepts through reflection, without starting with formalized stnciural concepts and then siudying concrete matertals of the concepts.

Now, let's examine the examples whete the concept of grow, one of the nosit bate algebrate structares, is translated into concrete examples and where the concept of group is constructed fom phenomena, and find out difterences. In teaching growp structure, instructors uswally give examples as follows: $\emptyset$ The set of all the symmentes of the rectangular(not the square) forms the group $Z_{2} \oplus Z_{2}$. 2 The set of $2 x_{2}$ matrices $G L_{2}(R)$, forms a group under muttiplication. (3) On the chutratie extersion feld $Q(\sqrt{2})$, identigy map $i$ and $z: a+b \sqrt{2} \rightarrow a-b \sqrt{2}$ forns the Galos grow of $Q(\sqrt{2})$ over $Q$.

The fact that the sets in these examptes form a group is verified by accurate calculations and the process has no errors. But the problem of this frame is that algorithm is repeated whenever a 


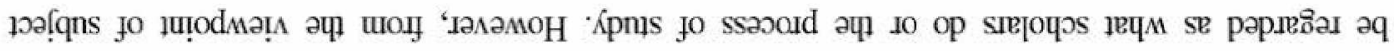

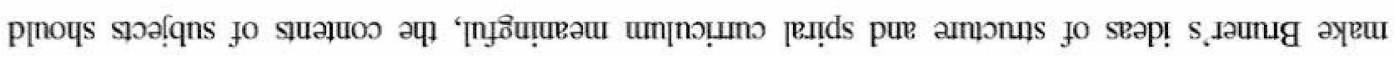

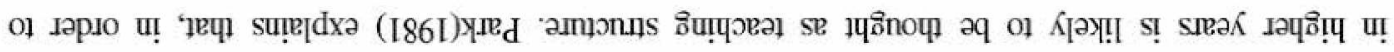

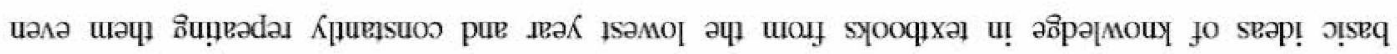

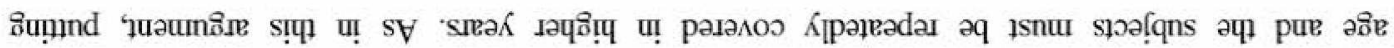

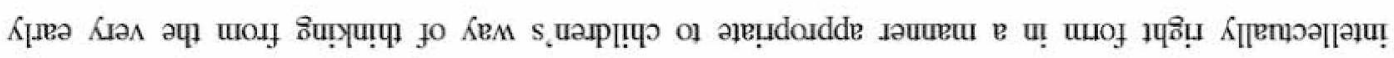
แ!

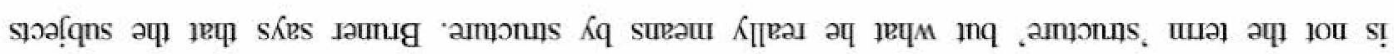

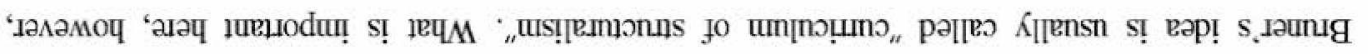

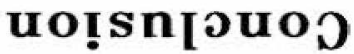

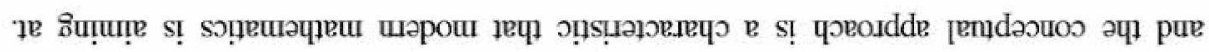

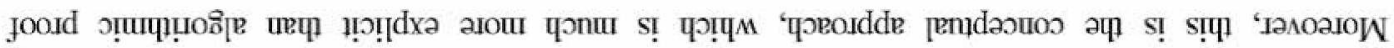

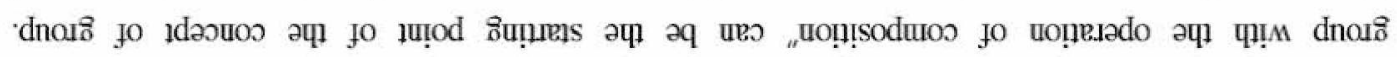

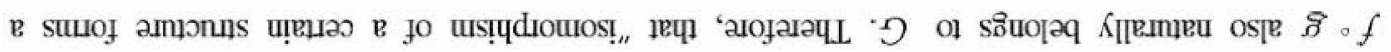

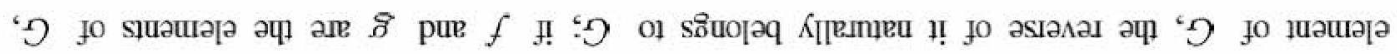

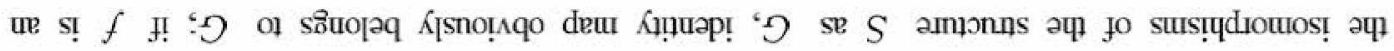

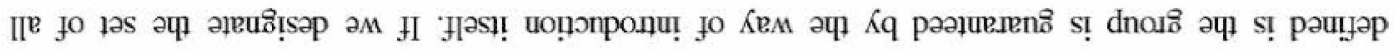

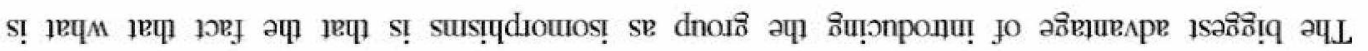

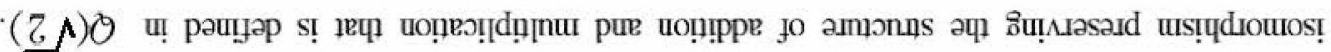

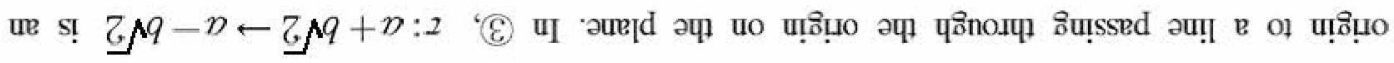

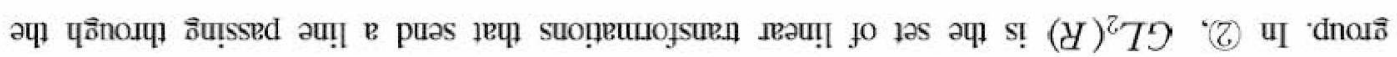

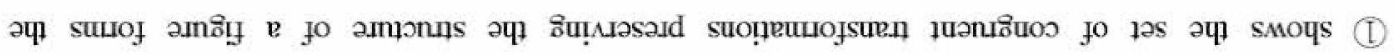

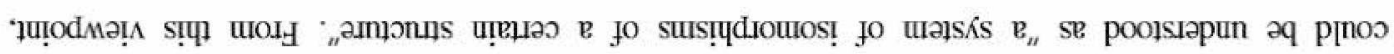

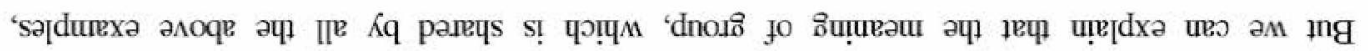

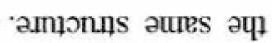

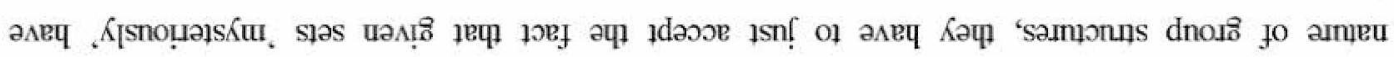

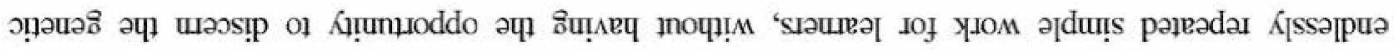

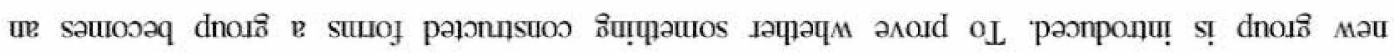


matter education, which is closely related to the contents of knowledge, such explanation is just indefinite. Bruner himself suggests EIS theory in an attempt to apply the idea of spiral curriculum to the concrete contents of subjects, but it reveals many theoretical limits.

Piaget's operational constructivism emphasizes that the child ought to construct knowledge through his own activities and, especially, the source of logico-mathematical cognition should be operations or internalized actions. On the other hand, Bruner argues that the structure of knowledge is a fixed entity and the instructor should translate it into representation appropriate to the children's cognitive structure. Regardless of its intent, Bruner's argument seems to highlight the functional side of education or the educational method of transmitting given knowledge quickly and efficiently and, when knowledge is translated, its intellectual honesty is likely to be damaged.

The idea that the instructor should establish general ideas and principles of mathematics and level down them to the learners' level implies that the structure of mathematics is completed and it is a fixed intellectual system. However, in the view of structuralism including Piaget's, structure is the transformational system which is developing and changing. If this gets involved with the contents of subjects, the learner's developing structure of knowledge entails the qualitative differences in the level, and the mechanism of reflective abstraction like "content $\rightarrow$ form $\rightarrow$ more refined content $\rightarrow$ new form $\rightarrow$..." becomes a key part which constitutes the structure.

Freudenthal argues that to help the learner understand the structure of mathematics, the learner needs to experience the structuralization, through which he organizes phenomena into mathematical structures. The direction of the structuralization or the organization is directly opposite to knowing the formal meaning of a certain structure and dealing with a few phenomena with the structure as examples. In order to realize the premise that the mathematical structure should be learned not as what is given to the learner but as what the learner himself should construct, it is necessary to research more intensively on the nature of mathematical structure and the phenomena in the real world, which can be mathematized into the structure. 


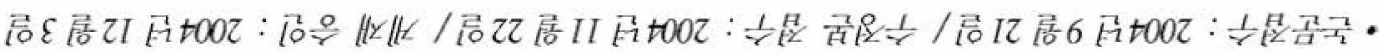

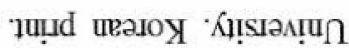

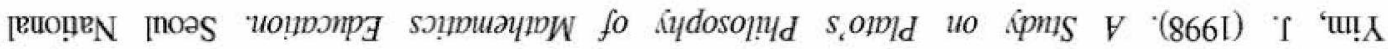

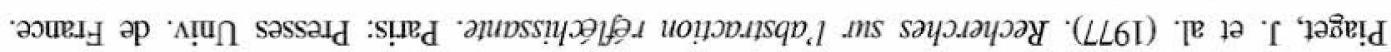
गाI 'syoog

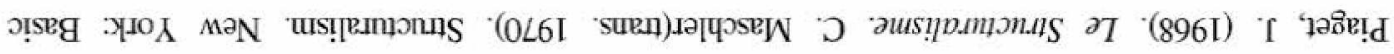

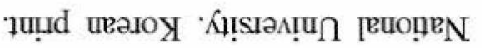

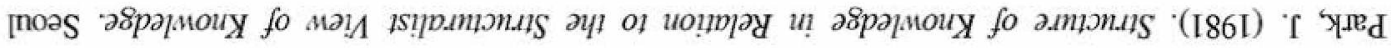

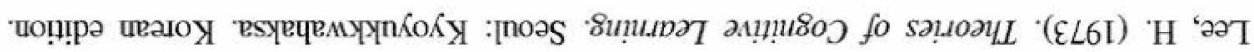
'ssajd

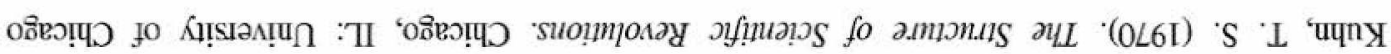

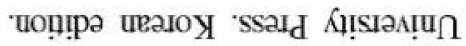

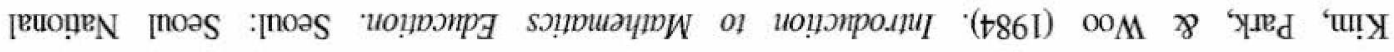

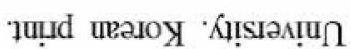

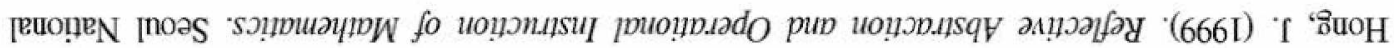
Кরueduo

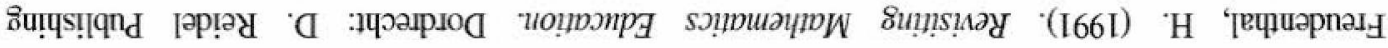

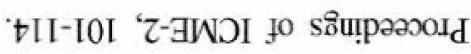

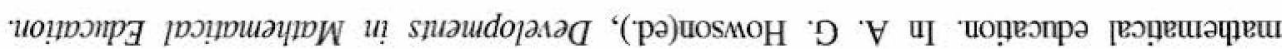

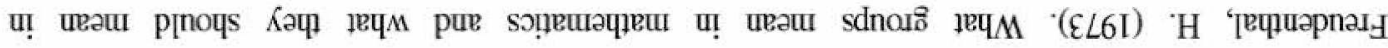

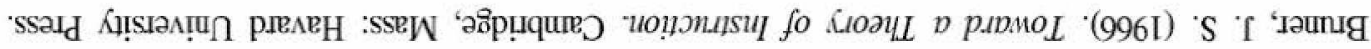

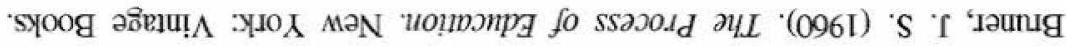

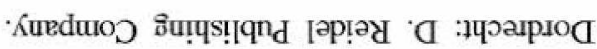

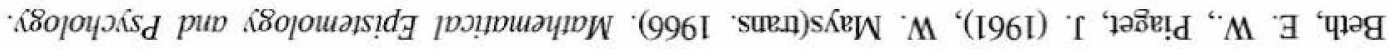
әวนวләศวบ 


\section{초 록}

수학적 구조의 의미에 대한 교육학적 고찰

$$
\begin{array}{r}
\text { 홍 진 곤 } \\
\text { (건국대학교 교수) }
\end{array}
$$

본 연구는 뼤아제의 발생적 인식론과 구조주의에 대한 고찰을 바탕으로, 부르바키 학 파기 주장하는 수학의 모구조와 삐아제기 말하는 수학적 사고의 구조기 교왁적 관점에서 어떻게 관련을 맺는지 살펴보았고, 지식의 구조가 가져야 하는 본질적인 특성을 검토하면 서 변형과 발달이 핵심적인 문제가 됨을 지적하였다. 이에 비추어 브루녀의 구조 개념이 갖는 한계를 지적하였으며, 수학적 개념으로서의 대수적 구조를 학습자가 구성하게 하는 문제를 논의하였다.

주제어 : 구조주의, 발생적 인식론, 구조 